\title{
FAKTOR PENYEBAB KERUSAKAN LINGKUNGAN SEKITAR AKIBAT PEMBANGUNAN UNDERPASS STUDI KASUS : UNDERPASS MAKAMHAJI, SUKOHARJO
}

\author{
Masyiana Arifah Alfia Riza 1* ), Satriya W Firmandhani 1), Tanty K A Iswardhani 2) \\ *) Corresponding author email : arifah@arsitektur.undip.ac.id \\ 1) Departemen Arsitektur, Fakultas Teknik, Universitas Diponegoro \\ 2) Departemen Arsitektur dan Perencanaan, Fakultas Teknik, Universitas Gadjah Mada
}

\author{
Article info \\ MODUL vol 18 no 2, issues period 2018 \\ Doi : https://doi.org/10.14710/mdl.18.2.2018.97-100 \\ Received : 22 Nov 2018 \\ Revised : - \\ Accepted : 22 Nov 2018
}

\begin{abstract}
Perlintasan kereta api merupakan salah satu faktor penyebab adanya pemberhentian kendaraan di suatu ruas jalan yang bila kondisi padat akan menyebabkan kemacetan. Dalam rangka mengantisipasi kemacetan dan memperlancar pergerakan transportasi maka diadakan suatu alternatif solusi semisal pelebaran jalan, pembangunan fly over, ataupun pembangunan underpass. Underpass adalah jalan melintang di bawah jalan lain atau persilangan tidak sebidang dengan membuat terowongan di bawah muka tanah. Jl. Slamet Riyadi di kelurahan Makamhaji, kecamatan Kartasura, Kabupaten Sukoharjo melakukan pembangunan underpass dimaksudkan untuk mengatasi kemacetan lalu lintas yang sering terjadi karena memang merupakan ruas jalan padat ditambah dengan perlintasan kereta api. Namun setelah selesai pembangunan dan difungsikan justru menimbulkan masalah-masalah baru terkait social dan lingkungan Tujuan dalam melakukan penelitian ini adalah agar mengetahui tentang faktor apa saja yang menjadi penyebab masalah lingkungan dan sosial pada proyek underpass ini timbul. Dari hasil analisis didapatkan 4 faktor yang menjadi penyebab kerusakan lingkungan oleh proyek underpass yaitu faktor pengetahuan dalam mengenal lokasi proyek, faktor pemanfaatan kelestarian alam dalam proyek underpass ini kurang bijaksana, faktor teknologi yang kurang memadai, dan faktor kerja sama antara pemerintah dengan warga .
\end{abstract}

Kata kunci : underpass, lingkungan, air tanah.

Masyiana Arifah Alfia Riza, Satriya W Firmandhani, Tanty K A Iswardhani

\begin{abstract}
Pendahuluan
Perlintasan kereta api merupakan salah satu faktor penyebab adanya pemberhentian kendaraan di suatu ruas jalan yang bila kondisi padat akan menyebabkan kemacetan. Dalam rangka mengantisipasi kemacetan dan memperlancar pergerakan transportasi maka diadakan suatu alternatif solusi semisal pelebaran jalan, pembangunan fly over atau underpass. Pada kasus di Jl. Slamet Riyadi di kelurahan Makamhaji, kecamatan Kartasura, Kabupaten Sukoharjo pembangunan underpass dimaksudkan untuk mengatasi kemacetan lalu lintas yang sering terjadi karena merupakan ruas jalan padat ditambah dengan perlintasan kereta api.
\end{abstract}
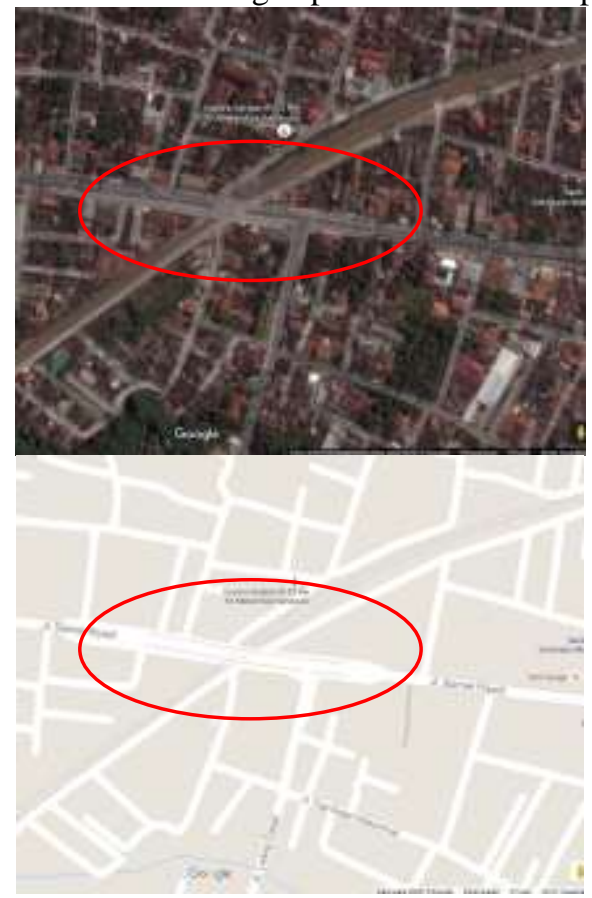

Gambar 1. Lokasi Underpass Makamhaji (https://www.google.co.id/maps, 2018) 
Berdasarkan sumber dari harian solopos.com proyek underpass ini dibangun sejak Mei 2012 dan dibuka pada pertengahan bulan Maret 2013. Kurang lebih 27 Milyar dana dikucurkan untuk pembangunan proyek ini. Namun dalam kenyataannya ternyata pembangunan underpass ini justru menimbulkan masalah baru yang berdampak pada lingkungan hidup area sekitar dan lingkungan sosial ekonomi masyarakat. Beberapa masalah yang diakibatkan yang menyangkut lingkungan hidup area sekitar adalah berkurangnya sumber air tanah warga sekitar dan terjadinya banjir pada ruas cekungan underpass karena kesalahan perhitungan proyek sehingga justru meyebabkan kemacetan karena pengalihan arus. Sedangkan dampak pada lingkungan sosial ekonomi warga adalah beberapa usaha warga di pinggir ruas jalan tersebut menjadi terhenti karena ditutup dengan beton underpass. Akibat dampak ini warga banyak yang berunjuk rasa membujuk pemerintah untuk menuntaskan masalah agar tidak ada yang dirugikan. Seperti dalam proyek Pembangunan Underpass di Simpang Dewa Ruci Kuta Bali ini hanya terdapat satu risiko yang signifikan terhadap waktu dan biaya yaitu muka air tanah yang tinggi (Dewi \& Nurcahyo, 2013).

Tujuan dalam melakukan penelitian ini adalah agar mengetahui tentang faktor apa saja yang menjadi penyebab masalah lingkungan dan sosial pada proyek underpass ini timbul. Sehingga dengan belajar dari kasus kali ini dapat menjadikan pelajaran dalam proyek selanjutnya.

\section{Kajian Pustaka}

Underpass adalah jalan melintang di bawah jalan lain atau persilangan tidak sebidang dengan membuat terowongan di bawah muka tanah (Prasetyo \& Sulardi, n.d.). Konstruksi yang digunakan harus tepat dalam pelaksanaan jalan underpass. Konstruksi underpass merupakan suatu galian dengan konstruksi struktur penahan tanah dalam posisi vertikal dimana sistem box tunnel / box underpass dipakai pada proyek underpass. Box underpass adalah sebuah panel terowongan dengan ukuran tertentu sebagai tempat lewatnya kendaraan pada underpass (Prasetyo \& Sulardi, n.d.). Box underpass ini harus kedap air dan kedap suara. Kedap air supaya air dari atas tidak merembes ke dalam box sedangkan kedap suara supaya suara bising dari lalu lintas diatasnya tidak terdengar sampai ke dalam box (Prasetyo \& Sulardi, n.d.).

Dalam penelitian kali ini lingkungan hidup yang menjadi pokok sasaran kajian adalah mengenai air tanah. Air tanah adalah salah satu bentuk air yang berada di sekitar bumi kita dan terdapat di dalam tanah. Air tanah pada umumnya terdapat dalam lapisan tanah baik dari yang dekat dengan permukaan tanah sampai dengan yang jauh dari permukaan tanah. Air tanah ini merupakan salah satu sumber air, ada saatnya air tanah ini bersih tetapi terkadang keruh sampai kotor, tetapi pada umumnya terlihat jernih (Sutand, Maria Christine. 2012). Selain tergantung pada curah hujan, air tanah juga akan berdampak pada perubahan lahan-lahan terbuka menjadi pemukiman dan industri, serta penebangan hutan tanpa kontrol. Hal tersebut akan sangat mempengaruhi infiltrasi terutama bila terjadi pada daerah resapan (recharge area) (USMAR \& HAKIM, 2006).

\section{Analisis dan Pembahasan}

Sebelum diadakannya underpass Jl. Slamet Riyadi dengan perlintasan kereta api memang cenderung padat. Pada jam-jam sibuk akan terjadi kemacetan yang cukup panjang. Untuk mengatasi masalah ini pemerintah mengadakan solusi adalah pembangunan underpass karena alternatif lain seperti pelebaran jalan dirasa kurang efektif dan jika pembangunan fly over terlalu memakan anggaran serta ketidakmampuan lahan. Setelah pembangunan underpass yang bertujuan untuk memperlancar lalu lintas justru terjadi masalah baru. Adapun beberapa dampak lingkungan yang terjadi dijelaskan berikut.

\section{Banjir Underpass \\ Pembangunan underpass yang kurang} mengetahui lingkungan sekitar menyebabkan banjir. Banjir diakibatkan karena hujan dan pipa penyedot pada underpass kurang efektif berfungsi serta aliran drainase yang tidak memadai. Pada bulan Maret 2015 lalu banjir menyebabkan genangan air dengan kedalaman sekitar $60 \mathrm{~cm}$ itu terjadi akibat derasnya curah hujan yang tak mampu diimbangi pompa air setempat. Satu mesin pompa air yang tersedia mati. Banjir terjadi lagi pada Desember 2015 endapan aspal sisa pengaspalan menyumbat drainase. Hal itu menyebabkan empat pompa air tak bekerja maksimal hingga mengakibatkan banjir. Segera setelah drainase dinormalisasi dan hujan berangsur reda, air tersedot pompa dan banjir pun lenyap.Akibatnya tak sedikit kendaraan yang melintas di banjir Sukoharjo itu mogok. Saat banjir terjadi tentu tidak dapat dilewati kendaraan sebagai jalur transportasi akibatnya banyak jalan yang dialihkan dan tidak memberikan alternatif kelancaran lalu lintas justru menambah masalah lalu lintas. pemerintah serius untuk menyelesaikan persoalan banjir yang kerap menerjang underpass Makamhaji. Pemerintah harus memperbaiki sistem saluran air dan mesin pompa di underpass Makamhaji. Dengan demikian, persoalan banjir underpass bisa tertangani. 


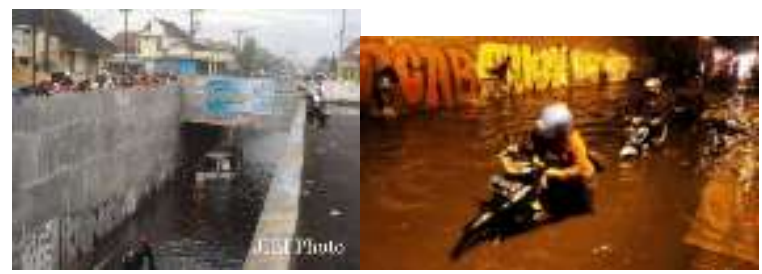

Gambar 2. Banjir yang terjadi di Underpass Makamhaji (www.solopos.com, 2015)

Saat penulis melakukan pantauan ke lokasi menurut penuturan warga setempat banjir sudah jarang terjadi. Sudah ada perbaikan dari pemerintah yang telah banyak mengeluarkan anggaran untuk perbaikan. Namun saat hujan masih terjadi genangan air yang kadang dikhawatirkan dapat meluap dan dapat menjadikan genangan besar sehingga banjir terjadi lagi.

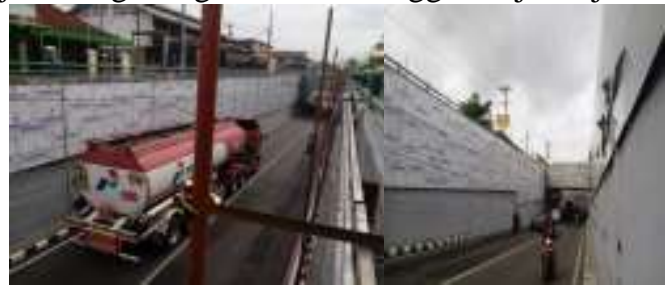

Gambar 3. Underpass Makamhaji pasca diperbaiki

\section{Jalan Ambles}

Pembangunan underpass berdampak pada amblesnya jalan disekitar warga. Pada Desember 2014 lalu dilansir dari solopos.com lokasi ambles berada tepat di sudut belokan jalur atau tak jauh dari tempat usaha jual nisan/kijing. Tanah yang ambles sedalam lebih dari 1,5 meter sepanjang lima langkah kaki orang dewasa dengan lebar tiga langkah kaki orang dewasa atau sampai di tengah jalur. Di lokasi tersebut terdapat rongga sepanjang lebih dari 0,5 meter. Jalur aspal yang bawahnya berongga itu retak. Saat diinjak dengan kekuatan biasa aspal tersebut ambles. Di sekitar lokasi diberi palang bambu agar pengguna jalan tidak melintas di dekat lubang. Selain di dekat sekitar lokasi, palang bambu juga terdapat di ujung jalur sisi utara. Warga memberi bambu itu agar mobil tidak dapat lewat di jalur. Kendati ambles jalur tersebut tetap dapat dilewati sepeda motor. Hanya, para pengendara harus lewat satu persatu untuk menghindari lokasi ambles. Kondisi tersebut terjadi pula di jalur yang sama tak jauh dari lokasi ambles di sudut belokan jalur itu. Jalur itu ambles dengan lebar sejengkal telapak tangan orang dewasa dengan panjang kurang lebih 150 meter. Jalan yang ambles tepat di tengah jalur. Kondisi tersebut mengganggu arus lalu lintas. Para pengendara melaju dengan kecepatan sedang sambil menghindari lokasi yang ambles agar tidak terperosok.

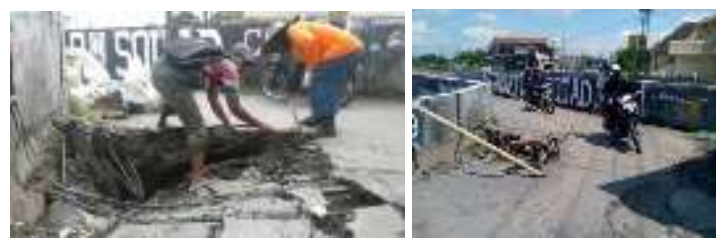

Gambar 4. Amblesnya jalan sekitar underpass (www.solopos.com, 2015)

Pantauan penulis saat tiba di lokasi amblesnya jalan telah diperbaiki. Namun jalan lebih kecil dengan hanya dapat diakses oleh kendaraan roda dua. Untuk mobil kecil yang dulunya masih dapat lewat dengan adanya perbaikan amblesnya jalan tersebut sekarang sudah tidak dapat lewat lagi kemungkinan untuk menghindari amblesnya tanah karena daya dukung tanah yang tidak kuat menahan beban.

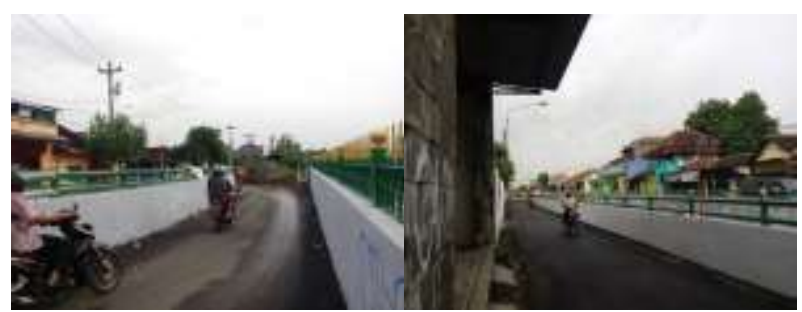

Gambar 5. Underpass Makamhaji pasca diperbaiki

\section{Mengeringnya Sumber Air Warga}

Setelah pembangunan underpass warga mengaku air sumur mereka tidak sederas yang dulu. Setelah dilakukan penyelidikan ternyata pada area underpass terdapat titik mata air yang kuat. Pembangunan underpass yang nota bene membuat cekungan menyebabkan aliran air turun mencari titik yang paling rendah menuju arah underpass. Di dalam pembangunan underpass terdapat sistem penyedot air untuk mengantisipasi tampungan air hujan ataupun sumber titik air agar tidak terjadi banjir. Namun dampaknya pada area air tanah warga menjadi mengering karena ikut tersedot dan tidak adanya aliran air hujan. Pemerintah berusaha mengusahakan untuk mengganti dengan PDAM namun sampai penulis turun ke lokasi belum ada realisasi PDAM yang diterima warga. Untuk mengatasi hal tersebut beberapa warga menggunakan cara manual yaitu mencari sumber air tanah yang lebih dalam lagi sebagai sumber air rumah tangga mereka.

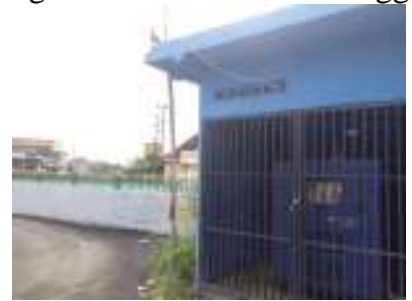

Gambar 6. Panel alat penyedot 
4. Mematikan sumber ekonomi warga

Ruas Jalan Slamet Riyadi merupakan sektor jalan utama yang sangat padat sehingga menjajikan aktifitas ekonomi yang terjadi di sepanjang jalan tersebut. Setelah pembangunan underpass berdampak pada matinya beberapa usaha warga akibat pengalihan dan penutupan jalur. Transportasi yang mulanya melewati kios-kios ataupun toko-toko warga ditutup dengan beton dan kendaraan masuk melewati jalur bawah underpass sehingga tidak lagi melewati dagangan mereka. Kendati diberikan jalur untuk tetap dapat mengakses ke tokotoko warga namun sangat terbatas pada kendaraan roda dua. Banyak kios yang akhirnya tutup karena merugi. Pemerintah tidak memeberikan kompensasi kepada warga yang ekonominya akhirnya gulung tikar karena proyek underpass ini atau memberikan alternatif baru untuk pengganti ekonomi mereka. Selain itu menurunya kondisi ekonomi mereka diperburuk dengan kondisi dodial mereka warga sekitar yang sekarang dipisahkan oleh tembok-tembok pembatas jalur underpass dan rel kereta api. Dulu warga hanya berseberangan sekarang sudah ditutup pagar dengan alasan keselamatan. Tentu hal ini menimbulkan masalah baru dengan adanya konflik sosial juga anti sosial antar warga yang disebabkan karena adanya pembangunan underpass.

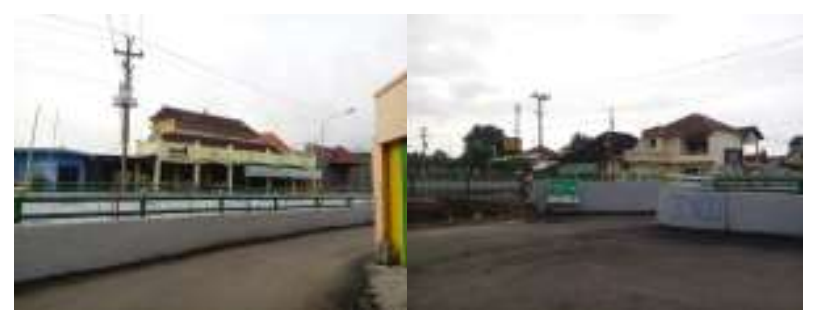

Gambar 7. Matinya ekonomi warga

\section{Kesimpulan}

Setelah dikaji diatas penulis dapat menarik beberapa poin dalam menjelaskan faktor yang mempengaruhi terjadinya perubahan lingkungan akibat proyek pembangunan underpass ini. Yang pertama adalah faktor pengetahuan dalam mengenal lokasi proyek mengenai lingkungan hidup terkait tanah dan air pada setiap lokus proyek underpass. Setiap lokus proyek mempunyai karakter tanah dan potensi air yang berbedabeda. Identifikasi yang mendalam tentang kedua hal ini dapat menjadi acuan penerapan struktur dan material yang akan digunakan sehingga tidak menimbulkan banjir. Selanjutnya faktor pemanfaatan kelestarian alam dalam proyek underpass ini kurang bijaksana. Dalam pembangunan proyek underpass ini sumber mata air yang berada di sekitar proyek justru ditutup ini dilakukan untuk mencegah air membanjiri proyek namun dampak lainnya adalah menjadikan sumber air warga ikut terhambat. Faktor teknologi yang kurang memadai membuat suatu masalah ditangani dengan lamban dan konvensioal. Ketika ada keruskaan tidak diperbaiki secara profesional justru menimbulkan masalah baru dan merugikan banyak masyarakat.

Selain itu faktor kerja sama antara pemerintah dengan warga dirasa sangat kurang. Pemerintah cenderung otoriter dalam keputusan pembuatan underpass hingga tidak mempedulikan dampak ekonomi sosial warga yang ditimbulkan.

Bila keempat faktor tersebut dapat diperhatikan dengan baik kedepannya proyek underpass dapat memberikan manfaat yang sebenarnya dengan tidak merusak lingkungan.

\section{Referensi}

Dewi, A. I., \& Nurcahyo, C. B. (2013). Analisa Risiko Pada Proyek Pembangunan Underpass Di Simpang Dewa Ruci Kuta Bali. Jurnal Teknik ITS, 2(2), C72--C77.

Prasetyo, S. D., \& Sulardi, S. (n.d.). PERANCANGAN BOX UNDERPASS DENGAN MENGGUNAKAN METODE KEKUATAN BATAS (ULTIMATE DESIGN).

USMAR, H., \& HAKIM, R. T. (2006). Pemanfaatan Air Tanah untuk Keperluan Air Baku Industri di Wilayah Kota Semarang Bawah. FAKULTAS TEKNIK.

Web

http://www.solopos.com/2015/05/06/gagasanunderpass-makamhaji-dan-tata-ruang-600999/2

http://www.solopos.com/?s=UNDERPASS+MAKA MHAJI\&sa=search 